\title{
Conversion of daily pegvisomant to weekly pegvisomant combined with long-acting somatostatin analogs, in controlled acromegaly patients
}

\author{
Sebastian J. C. M. M. Neggers • Wouter W. de Herder • \\ Richard A. Feelders • A. J. van der Lely
}

Published online: 8 January 2011

(c) The Author(s) 2011. This article is published with open access at Springerlink.com

\begin{abstract}
The efficacy of combined treatment in active acromegaly with both long-acting somatostatin analogs (SRIF) and pegvisomant (PEG-V) has been well established. The aim was to describe the PEG-V dose reductions after the conversion from daily PEG-V to combination treatment. To clarify the individual beneficial and adverse effects, in two acromegaly patients, who only normalized their insulin like growth factor (IGF-I) levels with highdose pegvisomant therapy. We present two cases of a 31 and 44 years old male with gigantism and acromegaly that were controlled subsequently by surgery, radiotherapy, SRIF analogs and daily PEG-V treatment. They were converted to combined treatment of monthly SSA and (twice) weekly PEG-V. High dose SSA treatment was added while the PEG-V dose was decreased during carful monitoring of the IGF-I. After switching from PEG-V monotherapy to SRIF analogs plus pegvisomant combination therapy IGF-I remained normal. However, the necessary PEG-V dose, to normalize IGF-I differed significantly between these two patients. One patient needed twice weekly $100 \mathrm{mg}$, the second needed $60 \mathrm{mg}$ once weekly on top of their monthly lanreotide Autosolution injections of $120 \mathrm{mg}$. The weekly dose reduction was 80 and $150 \mathrm{mg}$.
\end{abstract}

S. J. C. M. M. Neggers $(\bowtie)$. W. W. de Herder .

R. A. Feelders - A. J. van der Lely

Department of Medicine, Erasmus University Medical

Center Rotterdam, PO box 2040, 3000 CA Rotterdam,

The Netherlands

e-mail: s.neggers@erasmusmc.nl
After the introducing of lanreotide, fasting glucose and glycosylated haemoglobin concentrations increased. Diabetic medication had to be introduced or increased. No changes in liver tests or in pituitary adenoma size were observed. In these two patients, PEG-V in combination with long-acting SRIF analogs was as effective as PEG-V monotherapy in normalizing IGF-I levels, although significant dose-reductions in PEG-V could be achieved. However, there seems to be a wide variation in the reduction of $\mathrm{PEG}-\mathrm{V}$ dose, which can be obtained after conversion to combined treatment.

Keywords Pituitary tumor · Acromegaly · Acromegaly treatment · Pegvisomant - Combined treatment .

Somatostatin analogs

\section{Introduction}

Pegvisomant, a growth hormone $(\mathrm{GH})$ receptor antagonist is a highly effective medical therapy for acromegaly. Studies have reported on high efficacy of pegvisomant (PEG-V), alone or in combination with somatostatin analogs (SRIF) of $>90 \%$ to control insulin like growth factor (IGF-I) [1-4]. The necessary PEG-V dose to control IGF-I seems to be lower during combination therapy than with PEG-V alone [2, 5]. The combination treatment is probably therefore more effective at equal weekly dose than PEG-V alone $[2,3,5]$. There is a necessity to control IGF-I and GH has been well established since this will predict mortality $[6,7]$. So combined treatment seems to be an attractive option.

We present two cases of acromegaly patients who were controlled during daily, mono-therapy of PEG-V and were converted to combination treatment. 


\section{Subjects and methods}

Case report

Case A

A 31-years-old man was diagnosed with diabetes and gigantism since 1995, with a random $\mathrm{GH}$ of $220 \mathrm{mU} / \mathrm{l}$ and an IGF-I 4.5 times the upper limit of normal $(\times \mathrm{ULN})$. A macro adenoma of $3 \mathrm{~cm}$ with suprasellar extension, impingement of the chiasm and invasion in the left cavernous sinus which was assessed by the Magnetic Resonance Imaging (MRI). In 1996, the initial treatment was transsphenoidal surgery. Pathologist reported a pituitary adenoma which a positive immunohistochemical staining for GH. Postoperative the GH levels and IGF-I levels remained uncontrolled (Table 1). In 1997, 4 times daily subcutaneous injection of Octreotide $300 \mu \mathrm{g}$ was started and later converted to Octreotide LAR 30 mg monthly. In 1997, additional radiotherapy of 45 Gy in 25 fractions was given. In 1998, despite all these efforts IGF-I and GH remained elevated while other anterior pituitary hormones became deficient, which needed replacement therapy. Therefore, this patient was switched to pegvisomant therapy. Octreotide LAR was stopped in 1998 and daily PEG-V was increased up to $40 \mathrm{mg}$ daily until IGF-I was within the age adjusted normal limits [4]. In October 2006 Lanreotide autosolution (LAN) was added and
PEG-V was decreased in dose and frequency according to protocol. On pituitary MRI prior to the introduction of the LAN a remnant $(8 \mathrm{~mm})$ of the adenoma was present in and around left cavernous sinus.

\section{Case B}

A 44-year-old man was diagnosed with acromegaly and osteoporosis since 1994. At the time of diagnose random GH serum levels were around $120 \mathrm{mU} / \mathrm{l}$ while IGF-I serum levels were around $3.5 \times$ ULN. On MRI, he had a pituitary tumor of $2-\mathrm{cm}$ with suprasellar extension, but without impingement of the chiasm and possible invasion of the right cavernous sinus. In 1994 he underwent transsphenoidal surgery. A tumor specimen revealed positive immunohistochemical staining for GH. After surgery, he was treated with radiotherapy (42 Gray in 32 fractions). After surgery and RT GH serum levels dropped to around $17 \mu \mathrm{g} / \mathrm{l}$. Three months post surgery IGF-I serum levels were decreased to $3.0 \times$ ULN. In 1995, Octreotide was started (100 $\mu$ g t.i.d.) and converted to monthly Octreotide LAR $40 \mathrm{mg}$ in 1998. Although he developed panhypopituitarism and GH levels normalized, IGF-I levels remained elevated, around $1.9 \times$ ULN (Table 1). In 2003, Octreotide LAR therapy was switched into PEG-V monotherapy. Daily PEG-V dosages of $30 \mathrm{mg}$ PEG-V were necessary to decrease IGF-I levels to within the age adjusted normal limits. In Marche

Table 1 Biochemical parameters and medication of both patients before and during combination therapy

\begin{tabular}{|c|c|c|c|c|c|c|c|c|}
\hline Patient A date & 1998 & 2000 & 2002 & 2003 & Jan-07 & Apr-07 & Jul-07 & Oct-07 \\
\hline $\begin{array}{l}\text { Acromegaly } \\
\text { medication }\end{array}$ & $\begin{array}{l}\text { Octreotide } \\
\text { LAR } 30\end{array}$ & $\begin{array}{l}\text { PEG-V } 40 \\
\text { OD }\end{array}$ & $\begin{array}{l}\text { PEG-V } 40 \\
\text { OD }\end{array}$ & $\begin{array}{l}\text { PEG-V } 40 \\
\text { OD }\end{array}$ & $\begin{array}{l}\text { LAN } 120 \\
\text { PEG-V } 70 \\
\text { mg TW }\end{array}$ & $\begin{array}{l}\text { LAN } 120 \\
\text { PEG-V } 80 \\
\text { mg TW }\end{array}$ & $\begin{array}{l}\text { LAN } 120 \\
\text { PEG-V } 100 \\
\text { mg TW }\end{array}$ & $\begin{array}{l}\text { LAN } 120 \\
\text { PEG-V } 100 \\
\text { mg TW }\end{array}$ \\
\hline $\mathrm{GH} \mu \mathrm{g} / 1$ & 42 & N/A & N/A & N/A & N/A & N/A & N/A & N/A \\
\hline IGF-I ULN (nmol/l) & $1.9(73,9)$ & $0.98(39.3)$ & $0.93(37.3)$ & $0.93(37.0)$ & $1.3(55.7)$ & $1.0(40.9)$ & $0.8(31.4)$ & $0.5(20.8)$ \\
\hline $\mathrm{HbA1c}$ & 6.9 & 6.4 & 6.1 & 6.2 & 8.4 & 8.7 & 9.0 & 7.7 \\
\hline Fasting glucose & 7.3 & 4.9 & 5.9 & 6.5 & 8.0 & 9.4 & 5.7 & 3.8 \\
\hline DM medication & INN TD 5 & INN TD 5 & INN TD 5 & INN TD 5 & INN TD 5 & INN TrD 5 & INN TrD 5 & $\begin{array}{l}\text { INN TD } 5 \\
\text { Glargin } 48 \\
\text { IE OD }\end{array}$ \\
\hline Patient B date & 2003 & 2004 & 2005 & 2006 & Jun-07 & Sep-07 & Dec-07 & Mar-07 \\
\hline Acromegaly medication & $\begin{array}{l}\text { Octreotide } \\
\text { LAR } 40\end{array}$ & $\begin{array}{l}\text { PEG-V } 30 \\
\text { OD }\end{array}$ & $\begin{array}{l}\text { PEG-V } 30 \\
\text { OD }\end{array}$ & $\begin{array}{l}\text { PEG-V } 30 \\
\text { OD }\end{array}$ & $\begin{array}{l}\text { LAN } 120 \\
\text { PEG-V } 50 \\
\text { mg TW }\end{array}$ & $\begin{array}{l}\text { LAN } 120 \\
\text { PEG-V } 80 \\
\text { mg OW }\end{array}$ & $\begin{array}{l}\text { LAN } 120 \\
\text { PEG-V } 60 \\
\text { mg OW }\end{array}$ & $\begin{array}{l}\text { LAN } 120 \\
\text { PEG-V } 60 \\
\text { mg OW }\end{array}$ \\
\hline $\mathrm{GH} \mu \mathrm{g} / 1$ & 2.3 & N/A & N/A & N/A & N/A & N/A & N/A & N/A \\
\hline IGF-I ULN (nmol/l) & $1.93(67.5)$ & $0.82(28.6)$ & $0.96(33.6)$ & $0.96(32.9)$ & $0.3(12.1)$ & $0.5(16.6)$ & $0.9(31.7)$ & $0.8(29.8)$ \\
\hline $\mathrm{HbA1c}$ & N/A & 6.6 & 6.3 & 6.4 & 6.9 & 7.8 & 8.9 & 7.4 \\
\hline Fasting glucose & 5.7 & 4.0 & 4.6 & 5.0 & 6.9 & 10.7 & 8.9 & 7.8 \\
\hline DM medication & none & none & none & none & none & MT 500 TD & MT $850 \mathrm{TrD}$ & MT $850 \mathrm{TrD}$ \\
\hline
\end{tabular}

LAN Lanreotide Autosolution (mg), $P E G$-V Pegvisomant (mg), $O D$ Once Daily, $O W$ Once Weekly, TW Twice Weekly, TD Twice Daily, $\operatorname{Tr} D$ Trice Daily, INN glibenclamide (mg), $M T$ metformin $(\mathrm{mg})$ and N/A 
2007, LAN was added and PEG-V was decreased in dose and frequency. On pituitary MRI prior to the introduction of the LAN, a small $(5 \mathrm{~mm})$ remnant of the adenoma was present close to the right cavernous sinus.

\section{Methods}

After monthly LAN $120 \mathrm{mg}$ was started the intervals between visits were 8 weeks to assess efficacy and safety. The initial dose of PEG-V was decreased with $50 \%$ and later a further stepwise decrease until IGF-I levels escaped (see results section). If IGF-I was above the upper limit of normal the dose was increased again until IGF-I levels were within the age adjusted normal range. If IGF-I fell below 0.5 ULN PEG-V dose was decreased. After normalization of IGF-I during the combination treatment phase, subjects visited our outpatient clinic every 12-16 weeks. If a pegvisomant injection dose reached $100 \mathrm{mg}$ or more, the administration of pegvisomant was divided into 2 (equal) dosages that were injected twice weekly.

From 2004 to 2009, IGF-I and GH concentrations were measured by an immunometric assays (Diagnostic Products Corporation, Los Angeles USA) and before by an immunoradiometric assays (Diagnostic Systems Laboratories, Texas USA). The IGF-I age adjusted reference ranges were used [8]. But during PEG-V treatment the GH serum levels were not assessed.

\section{Safety assessment included}

Fasting glucose, glycosylated haemoglobin, EKG, serum concentrations of alkaline phosphatase (AF), $\gamma$-glutamyltranspeptidase $(\gamma$-GT), alanine aminotransferase (ALT),

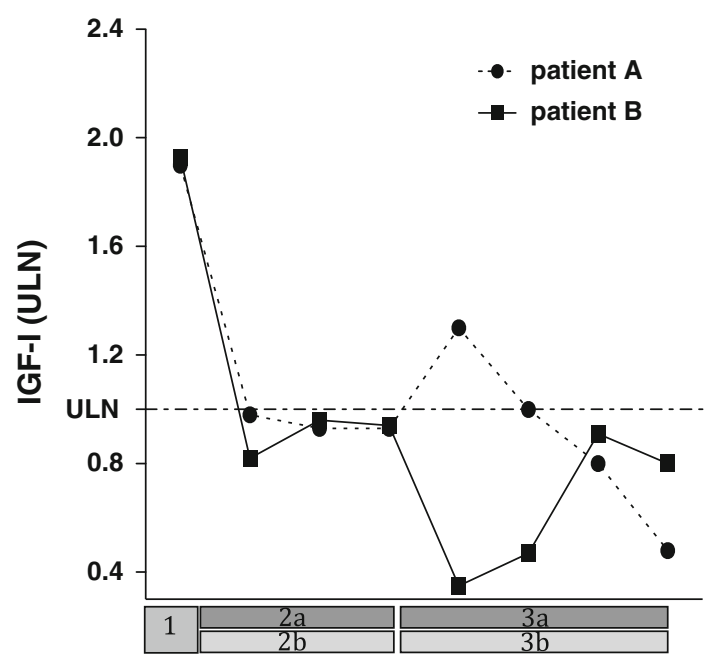

Fig. 11 Octreotide LAR $30 \mathrm{mg}, 2 a$ Pegvisomant $40 \mathrm{mg}$ daily, $2 b$ Pegvisomant $30 \mathrm{mg}$ daily, $3 a$ and $b$ Somatuline autosolution and Pegvisomant aspartate aminotransaminase (AST), lactate dehydrogenase (LD), total bilirubin and change in pituitary tumor volume. Tumor volume was assessed at baseline by MRI which was repeated every 12 months. Change in pituitary adenoma size was assessed by the same neuro-radiologist.

\section{Results}

LAN $120 \mathrm{mg}$ was given every 4 weeks. After the second administration of LAN 120 mg PEG-V dose was decreased by $50 \%$ of the normal total weekly dose of the subjects. PEG-V was increase until IGF-I normalized after 3 and/or 6 months (Table 1). Patient A was on $40 \mathrm{mg}$ PEG-V, daily. Patient's B original dose was $30 \mathrm{mg}$ a day of PEG-V. The dose reduction of PEG-V in patient $A$ started with a dose decrease to twice weekly $70 \mathrm{mg}$ of PEG-V. Patient B decreased the PEG-V to twice weekly $50 \mathrm{mg}$. After 3 months patient A increased the dose to twice weekly $80 \mathrm{mg}$ and patient $\mathrm{B}$ decreased the dose to $80 \mathrm{mg}$ once weekly. After 6 months the final dose for patient A was twice weekly $100 \mathrm{mg}$ and for patient B once weekly $60 \mathrm{mg}$ of PEG-V.

The weekly PEG-V dose reduction for patient A was $80 \mathrm{mg}$ and patient B, $150 \mathrm{mg}$ weekly, both with a normalized IGF-I (Fig. 1).

\section{Safety}

Fasting glucose and glycosylated haemoglobin levels increased after introduction of LAN (Table 1). In patient 1, additional diabetic medication was necessary. Glargine up to $48 \mathrm{IE}$ was added on top of glibenclamide (5 $\mathrm{mg}$ b.i.d). Patient 2 had to start diabetic medication (metformin $850 \mathrm{mg}$ t.i.d.; Table 1). In these patients no transient elevated liver enzyme tests or tumor size increase was observed.

\section{Discussion}

We report two adequate controlled acromegaly patients during PEG-V monotherapy. Both could also be controlled after the conversion to combined treatment of PEG-V with long-acting SRIF analogs. During combined treatment, a dose reduction of PEG-V could be obtained between 80 and $150 \mathrm{mg}$ weekly to keep IGF-I levels within the ageadjusted reference range.

During long-term combined therapy the weekly mean dose of PEG-V was $77 \mathrm{mg}[2,9]$ while with PEG-V monotherapy a weekly mean dose of $130 \mathrm{mg}$ was necessary to reach an equal efficacy rate of more than 90\% [4]. Data from the long-term surveillance AcroStudy ${ }^{\mathrm{tm}}$ indicate 
that the mean patient on PEG-V therapy (of which around 1 out of 4 also use SRIF analogs) needs more than $21 \mathrm{mg}$ of PEG-V daily with an efficacy rate of around 60\% [10]. In our 2 patients that needed high-dose PEG-V during monotherapy, we observed dose reductions of 80 and $150 \mathrm{mg}$ per week, which reflect reductions in annual costs of around 35,000-65,000€ respectively. When we take into consideration that high-dose SRIF analogs treatment costs between 19,000 and 25,000 $€$, depending on the country, our data indicate that in patients who need high-dose PEG-V during monotherapy, a significant reduction in costs can be achieved without loosing efficacy in normalizing IGF-I levels. The ratio behind the dose reduction in PEG-V during combined therapy of LAN and PEG-V is an increase of about $20 \%$ in PEG-V serum levels [4, 11] and the decrease in GH serum levels due to SRIF analog treatment. Also, a direct and indirect inhibition of IGF-I generation of the liver by SRIF analogs [2, 4, 11-14] has been reported. Thus, during combined treatment PEG-V, which is a competitive antagonist of the $\mathrm{GH}$ receptor (GHR), has less $\mathrm{GH}$ to compete with, which reduces the necessary dose of PEG-V. Moreover, experiments in rodents, observed a decrease in the number of GHR on the liver due to a decrease of portal insulin concentration, which is a direct effect of SRIF analogs [12, 15, 16]. Therefore a further reduction in PEG-V dose can be possible.

The difference in dose reduction we observed between both patients might be explained by the expression level of subtype of the somatostatin receptor (SSTR) on the pituitary adenoma. Patient 1 might have a lower expression of sst2 than patient B, as the efficacy of SRIF analogs in suppressing pathological GH secretion depends on the expression level of the sst subtypes on the pituitary adenoma [17]. The expression level of sst2 on human pancreatic beta cells is high, but there remains controversy on the expression of sst3 and sst5 [18]. In vivo, octreotide, mainly an sst 2 agonist, decreases insulin concentration in contrast to Pasireotide (SOM 230) [17]. Pasireotide, with high affinity to the sst1 and sst5 as well, has as Octreotide hyperglycemic effect. There for it unclear what the effect of SOM 230 is on the GHR expression on the liver. The alternative treatment with SOM 230 in patient 1 might lead to a dose reduction since GH levels will be lower but because of the possible higher expression of GHR a higher dose of PEG-V could be needed. Thus it is unclear what the net effect will be beneficial for the PEG-V dose reduction. Finally most studies which have been conducted with SOM 230 where with diabetic patient that had an optimal control. Therefore it is questionable if this patient would really benefit from SOM 230.

SRIF analogs inhibits both exocrine and endocrine hormone secretion and to a lesser extent neuroendocrine tumor cell proliferation [19]. Activation of sst receptors decreases intra-cellular c-AMP generation through the inhibition of adenylyl cyclase. There seems to be a role of the GHRH cAMP signaling pathway in somatotroph tumorgenesis. Ectopic GHRH production leads to somatotroph hyperplasia, however rarely to adenoma formation [20]. GHRH induces c-AMP via a G-protein coupled receptor, the GHRH receptor, which induces $\mathrm{GH}$ production. Guanine nucleotide-binding protein (GNAS) mutation can lead to constitutively elevated c-AMP, protein kinase A activity, GH synthesis and secretion [21]. About $40 \%$ of sporadic somatotroph adenomas harbor this mutation. Although the percentage of patients using PEG-V that develop a clinical significant increase in tumor size is reassuring low [22, 23], the inhibitory effects of SRIF analogs on these mechanisms that are related to tumor growth also would suggest a more prominent role for the combination of both SRIF analogs and PEG-V, especially in patients with aggressive tumors and active disease that need high dose PEG-V during PEG-V monotherapy.

The disadvantage of SRIF analogs treatment compared to PEG-V treatment with respect to carbohydrate metabolism is clearly demonstrated here. In healthy volunteers, administration of PEG-V did not influence the fasting insulin and glucose or response to oral glucose loading, in contrast with octreotide [24]. Short term combined treatment resulted in a lower fasting glucose than with SRIF analogs alone, without a change in insulin levels [11]. During long-term studies a decrease in glycosylated haemoglobin could be observed despite the reduction of insulin or oral diabetic medication [2, 3]. It seems that in the hierarchy of the beneficial effects on carbohydrate metabolism, PEG-V as monotherapy is superior to combined treatment. However, the combination is better than SRIF analogs monotherapy.

In the past, both patients were treated with conventional radiotherapy. This was the pre-PEG-V era. To date, radiotherapy has become redundant from efficacy point of view. After a mean duration of 10 years remission rates of $50-60 \%$ are reported, but also $50-80 \%$ of subjects develop hypopituitarism as well [25]. Radiotherapy has some more disadvantages. A decreased quality of life has been reported which seems to be progressive over time [26] and radiotherapy might also increase mortality (SMR 2.68) mainly due to cerebrovascular mortality [27]. Our patients already showed some long-term side effects of radiotherapy as both have hypopituitarism. Cerebrovascular accidents have not occurred to date.

These two cases are different from our previous reports, because these two patients were previously treated controlled with PEG-V daily monotherapy. Our previous studies included patients on SRIF analogs that still had an elevated IGF-I and therefore we did not have a direct comparison for dose reduction of PEG-V. 
In this case-study we start immediately with high-dose SRIF analogs treatment and we reduce weekly dose of pegvisomant by $50 \%$. After 3 and 6 months, the PEG-V can be adjusted according to the serum IGF-I levels, If elevated, a higher weekly dose is necessary, while in case of normal IGF-I levels, one could further reduce the PEG-V dosages to find the lowest effective dose.

In conclusion, these two case-reports show that a dose reduction in PEG-V is possible after the addition of a monthly high dose SRIF analogs. This might significantly reduce the annual costs. However, deterioration in the carbohydrate metabolism should be taken into account.

Conflict of interest W. W. de Herder and A. J. van der Lely are consultants for Novartis Pharma and Ipsen Pharma International. A. J. van der Lely is also a consultant for Pfizer International. R. A. Feelders is consultants for Novartis Pharma. The other author has nothing to disclose.

Open Access This article is distributed under the terms of the Creative Commons Attribution Noncommercial License which permits any noncommercial use, distribution, and reproduction in any medium, provided the original author(s) and source are credited.

\section{References}

1. Feenstra J, de Herder WW, ten Have SM, van den Beld AW, Feelders RA, Janssen JA, van der Lely AJ (2005) Combined therapy with somatostatin analogues and weekly pegvisomant in active acromegaly. Lancet 365(9471):1644-1646

2. Neggers SJ, de Herder WW, Janssen JA, Feelders RA, van der Lely AJ (2009) Combined treatment for acromegaly with longacting somatostatin analogs and pegvisomant: long-term safety for up to 4.5 years (median 2.2 years) of follow-up in 86 patients. Eur J Endocrinol 160(4):529-533

3. Neggers SJ, van Aken MO, Janssen JA, Feelders RA, de Herder WW, van der Lely AJ (2007) Long-term efficacy and safety of combined treatment of somatostatin analogs and pegvisomant in acromegaly. J Clin Endocrinol Metab 92(12):4598-4601

4. van der Lely AJ, Hutson RK, Trainer PJ, Besser GM, Barkan AL, Katznelson L, Klibanski A, Herman-Bonert V, Melmed S, Vance ML, Freda PU, Stewart PM, Friend KE, Clemmons DR, Johannsson G, Stavrou S, Cook DM, Phillips LS, Strasburger CJ, Hackett S, Zib KA, Davis RJ, Scarlett JA, Thorner MO (2001) Long-term treatment of acromegaly with pegvisomant, a growth hormone receptor antagonist. Lancet 358(9295): 1754-1759

5. Hodish I, Barkan A, Medscape (2008) Long-term effects of pegvisomant in patients with acromegaly. Nat clin pract 4(6):324-332

6. Dekkers OM, Biermasz NR, Pereira AM, Romijn JA, Vandenbroucke JP (2008) Mortality in acromegaly: a metaanalysis. J clin Endocrinol Metab 93(1):61-67

7. Holdaway IM, Bolland MJ, Gamble GD (2008) A meta-analysis of the effect of lowering serum levels of GH and IGF-I on mortality in acromegaly. Eur J Endocrinol 159(2):89-95

8. Elmlinger MW, Kuhnel W, Weber MM, Ranke MB (2004) Reference ranges for two automated chemiluminescent assays for serum insulin-like growth factor I (IGF-I) and IGF-binding protein 3 (IGFBP-3). Clin Chem Lab Med 42(6):654-664
9. Neggers SJ, van der Lely AJ (2009) Somatostatin analog and pegvisomant combination therapy for acromegaly. Nat Rev Endocrinol 5(10):546-552

10. Trainer PJ, Ezzat S, D’Souza GA, Layton G, Strasburger CJ (2009) A randomized, controlled, multicentre trial comparing pegvisomant alone with combination therapy of pegvisomant and long-acting octreotide in patients with acromegaly. Clin Endocrinol 71(4):549-557

11. Jorgensen JO, Feldt-Rasmussen U, Frystyk J, Chen JW, Kristensen LO, Hagen C, Orskov H (2005) Cotreatment of acromegaly with a somatostatin analog and a growth hormone receptor antagonist. J Clin Endocrinol Metab 90(10):5627-5631

12. Leung KC, Doyle N, Ballesteros M, Waters MJ, Ho KK (2000) Insulin regulation of human hepatic growth hormone receptors: divergent effects on biosynthesis and surface translocation. J Clin Endocrinol Metab 85(12):4712-4720

13. Neggers SJ, van Aken MO, de Herder WW, Feelders RA, Janssen JA, Badia X, Webb SM, van der Lely AJ (2008) Quality of life in acromegalic patients during long-term somatostatin analog treatment with and without pegvisomant. J Clin Endocrinol Metab 93(10):3853-3859

14. Murray RD, Kim K, Ren SG, Chelly M, Umehara Y, Melmed S (2004) Central and peripheral actions of somatostatin on the growth hormone-IGF-I axis. J Clin Investig 114(3):349-356

15. Shishko PI, Dreval AV, Abugova IA, Zajarny IU, Goncharov VC (1994) Insulin-like growth factors and binding proteins in patients with recent-onset type 1 (insulin-dependent) diabetes mellitus: influence of diabetes control and intraportal insulin infusion. Diabetes Res Clin Pract 25(1):1-12

16. Wurzburger MI, Prelevic GM, Sonksen PH, Balint-Peric LA, Wheeler M (1993) The effect of recombinant human growth hormone on regulation of growth hormone secretion and blood glucose in insulin-dependent diabetes. J Clin Endocrinol Metab 77(1):267-272

17. van der Hoek J, de Herder WW, Feelders RA, van der Lely AJ, Uitterlinden $\mathrm{P}$, Boerlin V, Bruns $\mathrm{C}$, Poon $\mathrm{KW}$, Lewis I, Weckbecker G, Krahnke T, Hofland LJ, Lamberts SW (2004) A single-dose comparison of the acute effects between the new somatostatin analog SOM230 and octreotide in acromegalic patients. J Clin Endocrinol Metab 89(2):638-645

18. Strowski MZ, Blake AD (2008) Function and expression of somatostatin receptors of the endocrine pancreas. Mol Cell Endocrinol 286(1-2):169-179

19. Melmed S (2009) Acromegaly pathogenesis and treatment. J Clin Investigation 119(11):3189-3202. doi:10.1172/JCI39375

20. Thorner MO, Perryman RL, Cronin MJ, Rogol AD, Draznin M, Johanson A, Vale W, Horvath E, Kovacs K (1982) Somatotroph hyperplasia. Successful treatment of acromegaly by removal of a pancreatic islet tumor secreting a growth hormone-releasing factor. J Clin Investigation 70(5):965-977

21. Vallar L, Spada A, Giannattasio G (1987) Altered Gs and adenylate cyclase activity in human GH-secreting pituitary adenomas. Nature 330(6148):566-568

22. Buhk JH, Jung S, Psychogios MN, Goricke S, Hartz S, SchulzHeise S, Klingebiel R, Forsting M, Bruckmann H, Dorfler A, Jordan M, Buchfelder M, Knauth M (2010) Tumor volume of growth hormone-secreting pituitary adenomas during treatment with pegvisomant: a prospective multicenter study. J Clin Endocrinol Metab 95(2):552-558. doi:10.1210/jc.2009-1239

23. Trainer PJ (2009) ACROSTUDY: the first 5 years. Eur J Endocrinol 161(Suppl 1):S19-24. doi:10.1530/EJE-09-0322

24. Parkinson C, Drake WM, Roberts ME, Meeran K, Besser GM, Trainer PJ (2002) A comparison of the effects of pegvisomant and octreotide on glucose, insulin, gastrin, cholecystokinin, and pancreatic polypeptide responses to oral glucose and a standard mixed meal. J Clin Endocrinol Metab 87(4):1797-1804 
25. Castinetti F, Morange I, Dufour H, Regis J, Brue T (2009) Radiotherapy and radiosurgery in acromegaly. Pituitary 12(1): 3-10. doi:10.1007/s11102-007-0078-y

26. van der Klaauw AA, Biermasz NR, Hoftijzer HC, Pereira AM, Romijn JA (2008) Previous radiotherapy negatively influences quality of life during 4 years of follow-up in patients cured from acromegaly. Clin Endocrinol 69(1):123-128
27. Ayuk J, Clayton RN, Holder G, Sheppard MC, Stewart PM, Bates AS (2004) Growth hormone and pituitary radiotherapy, but not serum insulin-like growth factor-I concentrations, predict excess mortality in patients with acromegaly. J Clin Endocrinol Metab 89(4):1613-1617 